\title{
Dual fluorescence and fast intramolecular charge transfer with 4-(diisopropylamino) benzonitrile in alkane solvents
}

\author{
Attila Demeter ${ }^{\mathrm{a}, 1}$, Sergey Druzhinin ${ }^{\mathrm{a}}$, Mathew George ${ }^{\mathrm{a}}$, Edwin Haselbach ${ }^{\mathrm{b}}$, \\ Jean-Luc Roulin ${ }^{\mathrm{b}}$, Klaas A. Zachariasse ${ }^{\mathrm{a}, *}$ \\ ${ }^{a}$ Max-Planck-Institut für biophysikalische Chemie, Spektroskopie und Photochemische Kinetik, D-37070 Göttingen, Germany \\ ${ }^{\mathrm{b}}$ Institut für Physikalische Chemie, Universität Fribourg, Perolles, CH-1700 Fribourg, Switzerland
}

Received 17 April 2000

\begin{abstract}
Dual fluorescence and fast intramolecular charge transfer (ICT) is observed with 4-(diisopropylamino)benzonitrile (DIABN) in alkane solvents. The rate constant $k_{a}$ for the reaction from the locally excited (LE) to the ICT state has a value of $3.4 \times 10^{11} \mathrm{~s}^{-1}$ in $n$-hexane at $25^{\circ} \mathrm{C}$, with an activation energy $E_{a}$ of $6 \mathrm{~kJ} \mathrm{~mol}^{-1}$. Efficient intersystem crossing with a yield of 0.94 takes place from the ICT state. With 4-(dimethylamino)benzonitrile, in contrast, dual fluorescence is not observed in alkanes. The charge transfer reaction of DIABN is mainly favoured by its small energy gap $\Delta E\left(S_{1}, S_{2}\right)$, in accordance with the PICT model for ICT in aminobenzonitriles. (c) 2000 Elsevier Science B.V. All rights reserved.
\end{abstract}

\section{Introduction}

The changes in molecular structure taking place in 4-(dimethylamino)benzonitrile (DMABN) and its dual fluorescent derivatives during the reaction from the initially prepared locally excited (LE) to the intramolecular charge transfer (ICT) state are the subject of continuing investigation [1-6]. In the twisted ICT (TICT) model [7,8], it is postulated that the dimethylamino group of DMABN undergoes a

\footnotetext{
* Corresponding author. Fax: +49-551-201-1501; e-mail: kzachar@gwdg.de

${ }^{1}$ On leave from the Institute of Chemistry, Chemical Research Center, Hungarian Academy of Sciences. P.O. Box 17, 1525 Budapest, Hungary.
}

twist of $90^{\circ}$ relative to the benzonitrile moiety, from a coplanar configuration in LE to a perpendicular structure in the ICT state. The planar ICT (PICT) model $[2,4,9,10]$, on the other hand, assumes that the ICT state of DMABN is largely planar, whereas its dimethylamino group in the LE state is considered to have retained at least part of the pyramidal configuration present in the ground state $[11,12]$. In the PICT model the magnitude of the energy gap $\Delta E\left(S_{1}, S_{2}\right)$ between the two lowest excited singlet states plays a crucial role [2]. The importance of the planarisation of the amino nitrogen during the LE $\rightarrow$ ICT reaction has been deduced from the strong reduction in the efficiency of the ICT reaction in the series of heterocyclic 4-aminobenzonitriles $\mathrm{P} n \mathrm{C}$ when the ring size $n$ of the amino substituent decreases from 8 to $3[9,10,13]$. For heterocyclic 
amines, the energy required for planarisation increases with decreasing ring size [14].

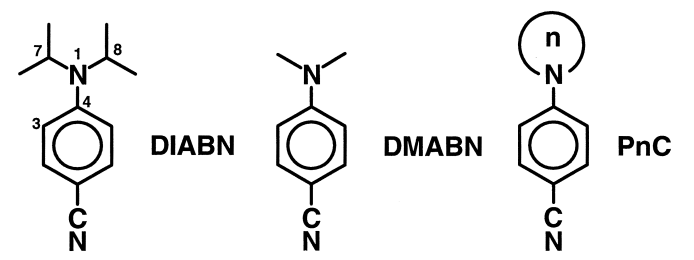

In tri(isopropyl)amine, the presence of three bulky isopropyl substituents results in a planarisation of the nitrogen atom $[15,16]$, with a clearly smaller pyramidal angle than that present in trimethylamine [17] and triethylamine [15]. Based on our assumption that the decrease of the pyramidality of the amino nitrogen is an important reaction coordinate in the ICT reaction of dual fluorescent aminobenzonitriles [9,10,13], 4-(diisopropylamino)benzonitrile (DIABN) was synthesized. The photophysical behaviour of DIABN in $n$-hexane and isopentane solution, derived from photostationary and time-resolved measurements as a function of temperature, is presented here. It should be noted that with DMABN, dual fluorescence is not observed in alkane solvents such as $n$-hexane $[8,18,19]$, even not at low temperatures, a condition under which an ICT emission is readily observed in the somewhat more polar solvents toluene and diethyl ether $[4,9,10,20]$.

\section{Experimental}

DIABN (mp $81-84^{\circ} \mathrm{C}$ ) was synthesised by bromination of $\mathrm{N}, \mathrm{N}$-diisopropylaniline (Aldrich), giving 4-bromo-N,N-diisopropylaniline [21], and subsequent replacement of the $\mathrm{Br}$-substituent by $\mathrm{CN}$ in a reaction with $\mathrm{CuCN}$ [22]. DMABN was obtained from Aldrich. For both aminobenzonitriles, HPLC was the last purification step.

The solvents $n$-hexane and isopentane (Merck, Uvasol) were used as received. The other solvents employed in the solvatochromic measurements were chromatographed over $\mathrm{Al}_{2} \mathrm{O}_{3}$ just prior to use. The solutions, with an optical density between 0.4 and 0.6 for the maximum of the first band in the absorp- tion spectrum, were deaerated by bubbling with nitrogen for $15 \mathrm{~min}$.

The fluorescence spectra were measured with a quantum-corrected Shimadzu RF-5000PC. Fluorescence quantum yields $\Phi_{\mathrm{f}}$, with an estimated reproducibility of $2 \%$, were determined with quinine sulfate in $1.0 \mathrm{~N} \mathrm{H}_{2} \mathrm{SO}_{4}$ as a standard $\left(\Phi_{\mathrm{f}}=0.546\right.$ at $\left.25^{\circ} \mathrm{C}[23]\right)$.

The fluorescence decay times were determined with picosecond laser (excitation wavelength $\lambda_{\mathrm{exc}}$, 276 or $297 \mathrm{~nm})$ or nanosecond $\left(\lambda_{\text {exc }}, 296 \mathrm{~nm}\right)$ flashlamp single-photon counting (SPC) setups. These setups and the analysis procedure of the fluorescence decays have been described previously $[4,20]$. The instrument response function has a halfwidth of 20-35 ps.

The yields $\Phi_{\text {ISC }}$ of the intersystem crossing from the equilibrated $S_{1}$ state to the lowest triplet state $T_{1}$ were measured by $T-T$ absorption, using a method based on triplet energy transfer with perylene as the acceptor [24,25]. As a reference substance N-methyl1,8-naphthalimide was used, taking a value of 0.96 for $\Phi_{\text {ISC }}$ [26]. The solutions used in these experiments were degassed employing the freeze-pumpthaw method (5 cycles).

\section{Results and discussion}

\subsection{Molecular structure of DIABN}

The molecular structure of DIABN was determined by X-ray analysis [27]. The diisopropylamino group of DIABN (plane through $\mathrm{C}(7), \mathrm{N}(1)$ and $\mathrm{C}(8)$ ) is twisted over an angle of around $20^{\circ}$ relative to the plane of the phenyl ring, different from the not-twisted dimethylamino group in DMABN [11]. The dihedral angle $\mathrm{C}(3) \mathrm{C}(4) \mathrm{N}(1) \mathrm{C}(7)$ equals $24.3^{\circ}$, whereas an angle $\mathrm{C}(3) \mathrm{C}(4) \mathrm{N}(1) \mathrm{C}(8)$ of $174.6^{\circ}$ is found. The twist of the amino group in DIABN leads to a small lengthening of the N-phenyl bond N(1) C(4) (1.38 ̊) as compared with DMABN (1.37 $)$ [11], but this bond remains clearly shorter than that of 3,5-dimethyl-4-(dimethylamino)benzonitrile (MMD), with an N(1)-C(4) bond length of $1.41 \AA$ and an amino twist angle of $59^{\circ}$ [11]. In accordance with these observations, the absorption spectrum of 
DIABN is similar to that of DMABN (Fig. 1 and Section 3.4) and other 4-(dialkylamino)benzonitriles [5], but considerably different from that of MMD [19]. The pyramidality of the amino nitrogen N(1) in DIABN is slightly larger than in DMABN, as derived from the sum of the bond angles around $\mathrm{N}(1)$ : $357.5^{\circ}$ for DIABN and $358.8^{\circ}$ [11] for DMABN.

\subsection{Fluorescence spectra of DIABN and DMABN in $n$-hexane at $25^{\circ} \mathrm{C}$}

In the fluorescence spectrum of DMABN in $n$ hexane at room temperature only a single emission from the LE state is observed [18,19]. The occurrence of dual fluorescence cannot be detected (see Fig. 1). DIABN in $n$-hexane at $25^{\circ} \mathrm{C}$, in contrast, clearly is dual fluorescent. Its spectrum in Fig. 1 predominantly consists of an ICT emission (see Section 3.4) with a band maximum at around 26000 $\mathrm{cm}^{-1}$, strongly red-shifted with respect to the maximum of the much weaker LE emission $(\sim 29400$ $\mathrm{cm}^{-1}$ (Table 1)). The ICT/LE fluorescence quantum yield ratio $\Phi^{\prime}(\mathrm{ICT}) / \Phi(\mathrm{LE})$ has a value of around 27 (Table 1), indicating that already at $25^{\circ} \mathrm{C}$ the equilibrium of the ICT reaction is strongly shifted towards the ICT state [2].

\subsection{Absorption spectra of DIABN and DMABN: $\Delta E\left(S_{1}, S_{2}\right)$}

In the absorption spectrum of DMABN in $n$ hexane, the major $S_{2}$ band is clearly separated from the weaker structured $S_{1}$ band [19] (see Fig. 1). In the case of DIABN, the $S_{2}$ absorption band is redshifted relative to that of DMABN, leading to a strongly reduced energy gap $\Delta E\left(S_{1}, S_{2}\right)$ for the former molecule (Fig. 1). This observation is supported by linear dichroism measurements of DIABN and DMABN in stretched polyethylene films [28].

\subsection{Solvatochromic measurements: ICT dipole mo- ment $\mu_{\mathrm{e}}($ ICT) of DIABN}

To determine the dipole moment $\mu_{\mathrm{e}}$ of the redshifted main fluorescence band of DIABN (Fig. 1) and to verify its tentative identification given in Section 3.2. as coming from an ICT state, the energies $\tilde{\nu}^{\max }(\mathrm{flu})$ of the maxima of this emission band

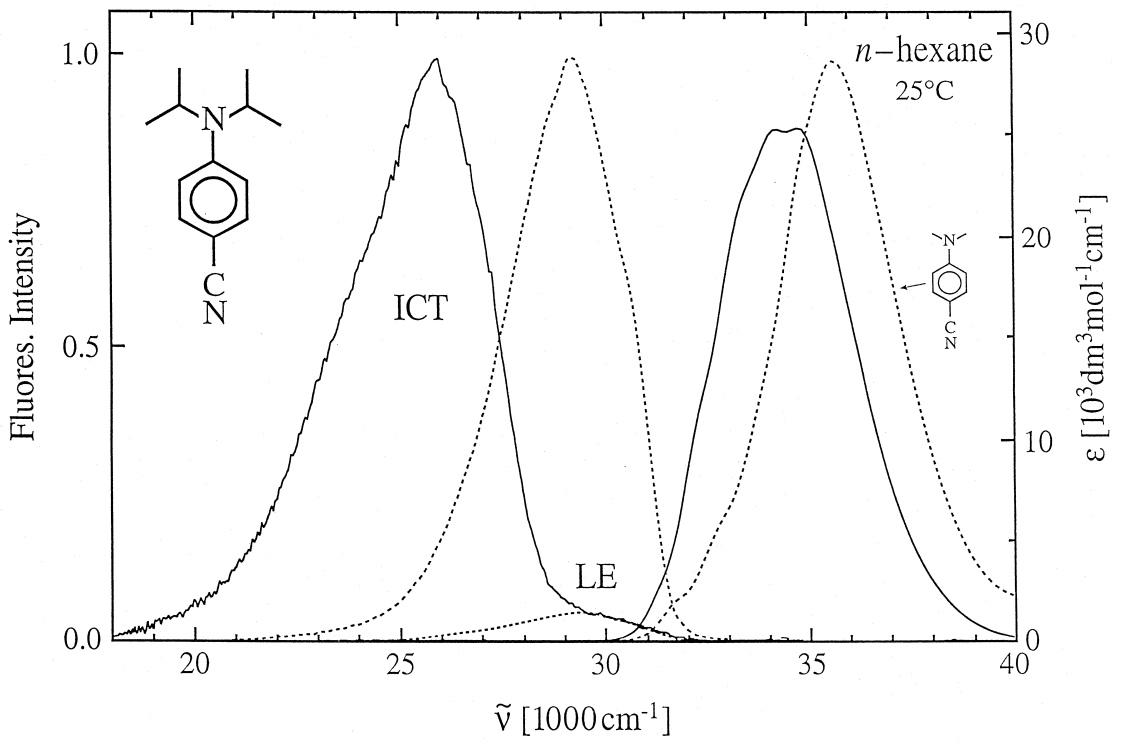

Fig. 1. Fluorescence and absorption spectra of (DIABN), full line, and 4-(dimethylamino)benzonitrile (DMABN), dashed line, in $n$-hexane at $25^{\circ} \mathrm{C}$. The fluorescence of DIABN consists of emissions from an LE and an ICT state. Excitation wavelengths: $280 \mathrm{~nm}$ (DIABN) and 290 nm (DMABN). 
Table 1

Energies $\tilde{\nu}^{\max }$ of the maximum of the ICT and the LE fluorescence bands and the absorption (abs) band of DIABN and DMABN in $n$-hexane (Fig. 1). The energy of the $S_{1}$ state $E\left(S_{1}\right)$, the extinction coefficient $\varepsilon^{\max }$ at $\tilde{\nu}^{\max }\left(\right.$ abs), the fluorescence quantum yields $\Phi^{\prime}(\mathrm{ICT})$ and $\Phi(\mathrm{LE})$ of the ICT and LE states and the yield $\Phi_{\text {ISC }}$ of intersystem crossing are also listed

\begin{tabular}{|c|c|c|c|c|c|c|c|c|c|c|}
\hline & $\begin{array}{l}T \\
\left({ }^{\circ} \mathrm{C}\right)\end{array}$ & $\begin{array}{l}\tilde{\nu}^{\max }(\mathrm{ICT}) \\
\left(1000 \mathrm{~cm}^{-1}\right)\end{array}$ & $\begin{array}{l}\tilde{\nu}^{\max }(\mathrm{LE}) \\
\left(1000 \mathrm{~cm}^{-1}\right)\end{array}$ & $\begin{array}{l}\tilde{\nu}^{\max }(\mathrm{abs}) \\
\left(1000 \mathrm{~cm}^{-1}\right)\end{array}$ & $\begin{array}{l}E\left(S_{1}\right)^{\mathrm{a}} \\
\left(1000 \mathrm{~cm}^{-1}\right)\end{array}$ & $\begin{array}{l}\varepsilon^{\max } \\
\left(\mathrm{M}^{-1} \mathrm{~cm}^{-1}\right)\end{array}$ & $\Phi^{\prime}(\mathrm{ICT})$ & $\Phi(\mathrm{LE})$ & $\Phi^{\prime}(\mathrm{ICT}) / \Phi(\mathrm{LE})$ & $\Phi_{\text {ISC }}$ \\
\hline DIABN & 25 & 26.05 & $(\sim 29.4)$ & $34.1-34.8$ & 31.2 & 25560 & 0.008 & $<3.0 \times 10^{-4}$ & $>27$ & $0.94 \pm 0.03^{\mathrm{b}}$ \\
\hline DIABN & -90 & 25.6 & 29.2 & - & - & - & 0.005 & $<6.0 \times 10^{-4}$ & $>7$ & $(0.995)^{\mathrm{c}}$ \\
\hline DMABN & 25 & - & 29.3 & 35.5 & 31.7 & 28860 & 0.0 & 0.18 & 0.0 & $0.76 \pm 0.03^{\mathrm{b}}$ \\
\hline
\end{tabular}

${ }^{\mathrm{a}}$ From crossing of absorption and fluorescence spectrum.

${ }^{\mathrm{b}}$ From $T-T$ absorption (see text)

${ }^{c}$ From $\Phi_{\mathrm{ISC}}^{\prime}(\mathrm{ICT})=k_{\mathrm{ISC}}^{\prime}(\mathrm{ICT}) \cdot \tau_{0}^{\prime}(\mathrm{ICT})$ and $\tau_{0}^{\prime}(\mathrm{ICT})=k_{\mathrm{f}}^{\prime}(\mathrm{ICT})+k_{\mathrm{ISC}}^{\prime}(\mathrm{ICT})$, under the assumption that internal conversion can be neglected (see data in Table 3 and text) Using the same procedure, a triplet yield $\Phi_{\mathrm{ISC}}^{\prime}(\mathrm{ICT})$ of 0.992 is obtained for DIABN in $n$-hexane at $25^{\circ} \mathrm{C}$ (see data in Table 3 ). 
were measured at $25^{\circ} \mathrm{C}$ as a function of solvent polarity. These data are plotted in Fig. 2a against the polarity parameter $f--f^{\prime}$ (Eqs. (1) and (2)) [29-31], as well as versus the ICT emission maxima $\tilde{\nu}^{\max }$ (ICT) of DMABN obtained in the same solvents (see Fig. 2b).

$$
\begin{aligned}
\tilde{\nu}^{\max }(f l u)= & \frac{-1}{4 \pi \varepsilon_{0}} \frac{2}{h c \rho^{3}} \mu_{e}\left(\mu_{e}-\mu_{g}\right)\left(f-f^{\prime}\right) \\
& + \text { const. }
\end{aligned}
$$

where

$f-f^{\prime}=\frac{\varepsilon-1}{2 \varepsilon+1}-\frac{n^{2}-1}{2 n^{2}+1}$.

In Eq. (1), $\rho$ is the equivalent spherical (Onsager) radius of the solute and $\varepsilon_{0}$ is the vacuum permittivity. The assumption is made that the dipole moment $\mu_{\mathrm{g}}^{\mathrm{FC}}$ of the Franck-Condon (FC) ground state reached upon emission from the relaxed $S_{1}$ state is identical with the ground state dipole moment $\mu_{\mathrm{g}}\left(S_{0}\right)$ [31].

From the slope of the plot in Fig. 2a, proportional to $\mu_{\mathrm{e}}\left(\mu_{\mathrm{e}}-\mu_{\mathrm{g}}\right) / \rho^{3}$ (Eq. (1)), a dipole moment $\mu_{\mathrm{e}}$ of $16 \pm 1 \mathrm{D}$ is obtained (Table 2) by adopting for DIABN the $\mu_{\mathrm{g}}$ value of 6.6 D measured for DMABN (supported by molecular mechanics calculations [32]). The radius $\rho$ is calculated by taking the molecular density of DIABN to be equal to unity [31]. The scatter in the data points (Fig. 2a), generally observed in this solvatochromic procedure, can be reduced by plotting the $\tilde{\nu}^{\max }($ ICT) data of DIABN against the corresponding maxima of DMABN, thereby mutually compensating specific solute/ solvent interactions.

The slope of this plot in Fig. $2 b$ is equal to the expression $\mu_{\mathrm{e}}(\mathrm{ICT})\left(\mu_{\mathrm{e}}(\mathrm{ICT})-\mu_{\mathrm{g}}(\mathrm{FC})\right) / \rho^{3}$ (see Eq. (1)) for DIABN divided by that for DMABN. From the value of $0.85 \pm 0.04$ for this slope, an ICT dipole moment $\mu_{\mathrm{e}}$ (ICT) of $18 \pm 1 \mathrm{D}$ is obtained for DIABN (Table 2), based on the dipole moment of $17 \mathrm{D}$ for the ICT state of DMABN, which has been determined by the TRMC method [33]. A similar value for $\mu_{\mathrm{e}}$ (ICT) was obtained for DMABN from an analysis of solvatochromic measurements [30]. The Onsager radius $\rho$ of DMABN was again calculated by assuming a molecular density of 1.0. In this second method (Fig. 2b), the impact of $\rho$ on the
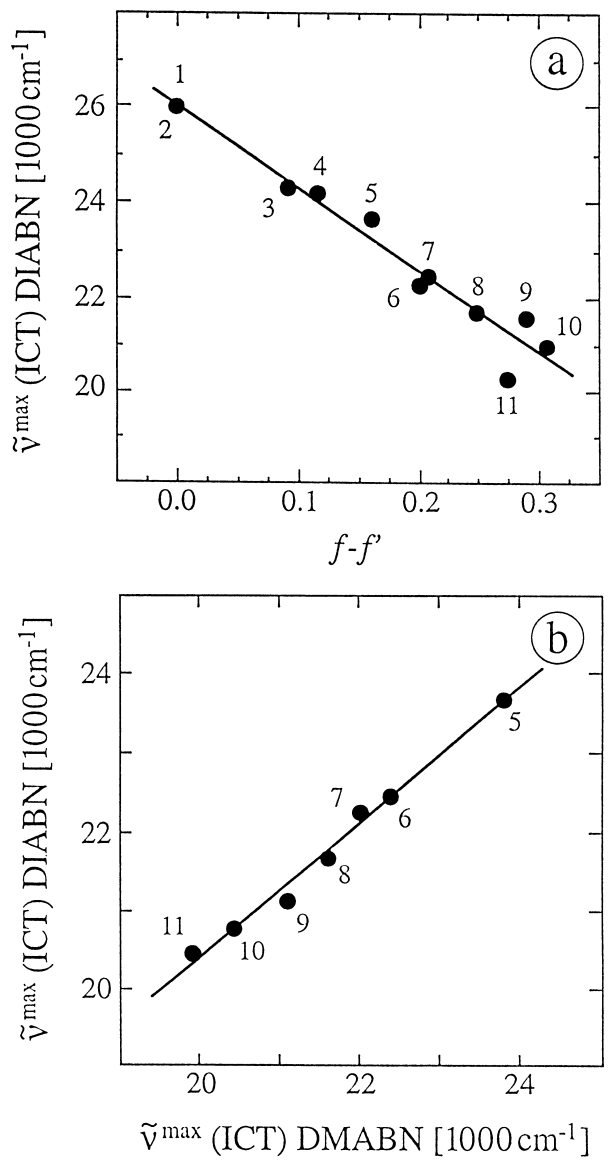

Fig. 2. Plots of the ICT emission maxima $\tilde{\nu}^{\max }(\mathrm{ICT})$ of (DIABN) in a series of solvents at $25^{\circ} \mathrm{C}$, against (a) the solvent polarity parameter $f-f^{\prime}$ (Eq. (2)) and (b) the corresponding $\tilde{\nu}^{\max }$ (ICT) data of 4-(dimethylamino)benzonitrile (DMABN). Solvents: (1) $n$-pentane, (2) $n$-hexane, (3) di(n-butyl) ether, (4) di(n-propyl) ether, (5) diethyl ether, (6) ethyl acetate, (7) tetrahydrofuran, (8) $n$-heptyl cyanide, (9) n-propyl cyanide, (10) acetonitrile, (11) $\mathrm{N}, \mathrm{N}$-dimethylformamide. Excitation wavelengths between 305 and $280 \mathrm{~nm}$

outcome of $\mu_{\mathrm{e}}$ (ICT) obviously is much smaller than when the ratio $\mu_{\mathrm{e}}(\mathrm{ICT})\left(\mu_{\mathrm{e}}(\mathrm{ICT})-\mu_{\mathrm{g}}\right) / \rho^{3}$ is used directly in the dipole moment determination (Fig. 2a). From the result now obtained for $\mu_{\mathrm{e}}(\mathrm{ICT})$ of DIABN, it is concluded that the strongly Stokesshifted main fluorescence band of DIABN in $n$ hexane (Fig. 1) indeed originates from an ICT state, with a similar dipole moment and hence intramolecular charge separation as that observed with DMABN. 
Table 2

Dipole moment $\mu_{\mathrm{e}}$ (ICT) of the ICT state and the activation energy $E_{a}$ and the pre-exponential factor $k_{a}^{0}$ of the ICT reaction in $n$-hexane of DIABN

\begin{tabular}{llll}
\hline $\begin{array}{l}\mu_{e}(\mathrm{ICT})^{\mathrm{a}} \\
(\mathrm{D})\end{array}$ & $\begin{array}{l}\mu_{e}(\mathrm{ICT})^{\mathrm{b}} \\
(\mathrm{D})\end{array}$ & $\begin{array}{l}E_{a}^{\mathrm{c}} \\
\left(\mathrm{kJ} \mathrm{mol}^{-1}\right)\end{array}$ & $\begin{array}{l}k_{a}^{0} \\
\left(10^{12} \mathrm{~s}^{-1}\right)\end{array}$ \\
\hline $18 \pm 1$ & $16 \pm 1$ & 5.7 & 3.5 \\
\hline
\end{tabular}

a Derived from the slope $(0.85 \pm 0.04)$ of the plot in Fig. $2 b$, with $\rho(\mathrm{DIABN})=4.31 \AA$ and $\rho(\mathrm{DMABN})=3.87 \AA$ (see Eq. (1).

b Derived from the slope $\left(-17200 \pm 1300 \mathrm{~cm}^{-1}\right)$ of the plot in Fig. 2a (see Eqs. (1) and (2).

${ }^{c}$ See Fig. 5 and text.

\subsection{Fluorescence quantum yields: influence of photoproducts}

The total fluorescence quantum yield $\Phi_{\mathrm{f}}$ of DIABN in $n$-hexane at $25^{\circ} \mathrm{C}$, equal to the sum of the quantum yields $\Phi^{\prime}$ (ICT) of the ICT and $\Phi(\mathrm{LE})$ of the LE emission, has a value of 0.008 (Table 1). It follows from the ratio $\Phi^{\prime}(\mathrm{ICT}) / \Phi(\mathrm{LE})$ of around 27 (Table 1) that the LE fluorescence quantum yield is very small: $3 \times 10^{-4}$. Due to this small yield $\Phi(\mathrm{LE})$, the presence of even minor amounts of photoproducts complicates the accurate determination of $\Phi^{\prime}(\mathrm{ICT}) / \Phi(\mathrm{LE})$. The value reported in Table 1 therefore is a lower limit.

With other 4-aminobenzonitriles, such a photodegradation is well-known. In the first publication on the dual fluorescence of DMABN, Lippert already pointed out that a photoproduct with a fluorescence spectrum similar to that of the LE emission is formed during irrradiation [18].

\subsection{Fluorescence spectra as a function of tempera- ture}

The fluorescence spectrum of DIABN in isopentane and $n$-hexane was measured as a function of temperature. The relative contribution of the LE emission to the dual fluorescence increases when the temperature is lowered (see Figs. 1 and 3). An influence of excitation wavelength (between 305 and $276 \mathrm{~nm}$ ) on the fluorescence spectra was not observed. The observation that the ratio $\Phi^{\prime}(\mathrm{ICT}) /$ $\Phi(\mathrm{LE})$ becomes smaller with decreasing temperature, indicates that DIABN is in the low-temperature limit, at which for the rate constant $k_{d}$ of the ICT $\rightarrow$ LE back reaction and the ICT lifetime $\tau_{0}^{\prime}$ the condition $k_{d}<<1 / \tau_{0}^{\prime}$ holds [4], normally an indication of a large ICT reaction enthalpy $-\Delta H$ (see Section 3.9). From the slope of the Stevens-Ban plots (not shown) of $\ln \left(\Phi^{\prime}(\mathrm{ICT}) / \Phi(\mathrm{LE})\right.$ ) versus $1000 \mathrm{~T}^{-1}$, equal to $-E_{a} / R[3,20]$, an ICT activation energy $E_{a}$ for DIABN of $4 \pm 1 \mathrm{~kJ} \mathrm{~mol}^{-1}$ in $n$-hexane and $k-d$ of $5.5 \pm 0.5 \mathrm{~kJ} \mathrm{~mol}^{-1}$ in isopentane is obtained. Note that the appearance of structure in the ICT emission bands in Fig. 3 is not a common feature for aminobenzonitriles [1,2,4-10]. It is likewise observed with the strongly dipolar (21 D) fluorescence bands of electron donor/acceptor stilbenes such as 4-(dimethylamino)-4'-cyanostilbene (DCS)

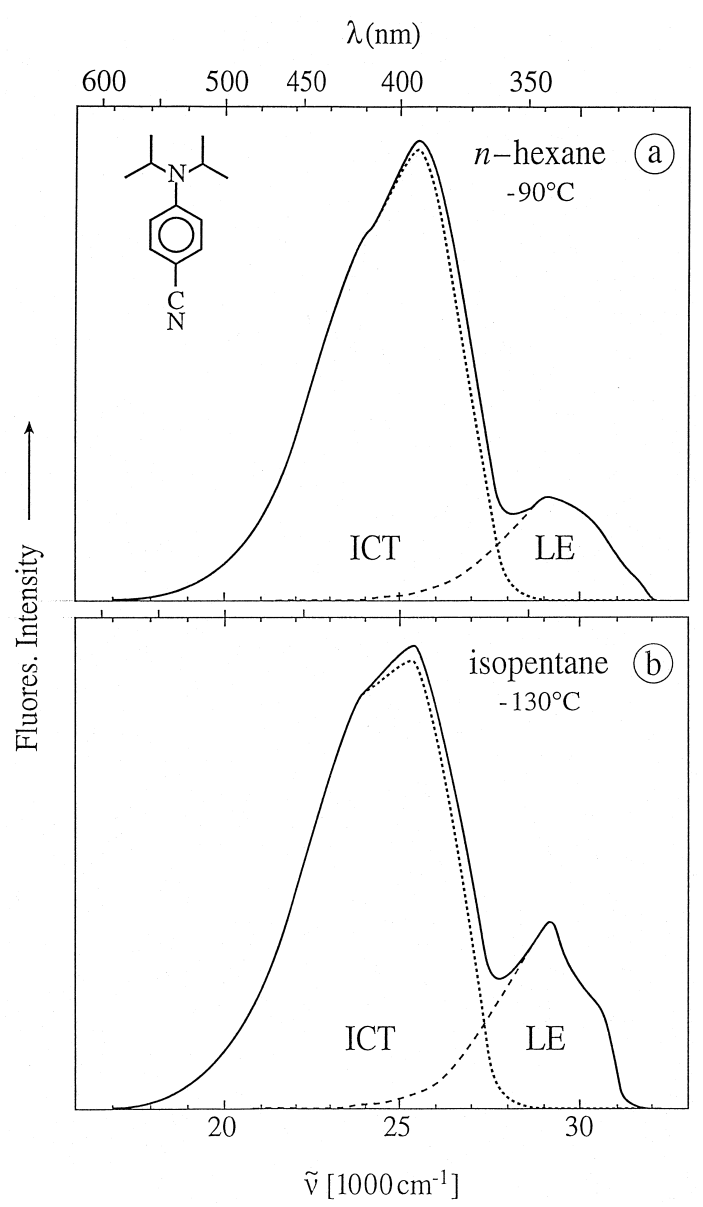

Fig. 3. Fluorescence spectra of DIABN in (a) $n$-hexane at $-90^{\circ} \mathrm{C}$ and (b) isopentane at $-130^{\circ} \mathrm{C}$. The separate emissions from the LE and ICT states are shown. Excitation wavelength: $280 \mathrm{~nm}$. 
in alkane solvents [31]. As well for DIABN and the other dual fluorescent 4-aminobenzonitriles as for DCS, structureless and symmetric emission bands are found in solvents more polar than alkanes [4,8,31].

\subsection{Intersystem crossing yields at $25^{\circ} \mathrm{C}$ : no internal conversion}

For DIABN in $n$-hexane at $25^{\circ} \mathrm{C}$ a triplet yield $\Phi_{\text {ISC }}$ of $0.94 \pm 0.03$ is determined. The sum of $\Phi_{\text {ISC }}$ and the total fluorescence quantum yield $\Phi_{\mathrm{f}}$ does not deviate appreciably from unity $(0.95 \pm 0.03$ (Table 1)). It hence follows that internal conversion (IC) is not an important deactivation pathway for DIABN

in $n$-hexane at room temperature.

\subsection{LE and ICT fluorescence decays in n-hexane at $-90^{\circ} \mathrm{C}$}

A global analysis [4] of the fluorescence decays $i_{\mathrm{f}}(\mathrm{LE})$ and $i_{\mathrm{f}}(\mathrm{ICT})$ of DIABN in $n$-hexane at $-90^{\circ} \mathrm{C}$

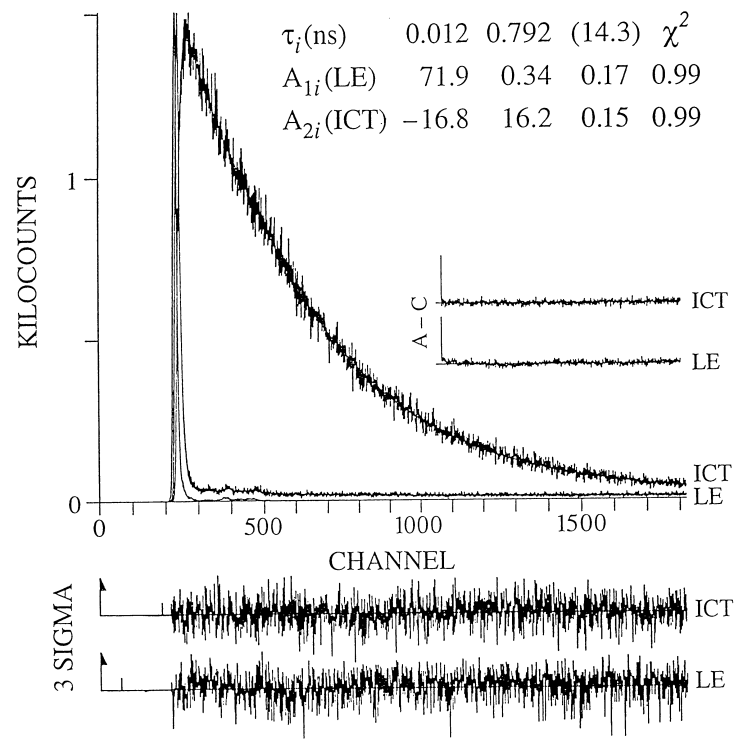

Fig. 4. LE and ICT fluorescence response functions of DIABN in $n$-hexane at $-90^{\circ} \mathrm{C}$. The LE and ICT decays are analysed simultaneously (global analysis). The decay times $\left(\tau_{2}, \tau_{1}\right)$ and their pre-exponential factors $A_{1 i}$ and $A_{2 i}$ are given (Eqs. (3) and (4)). The shortest decay time $\tau_{2}$ is listed first. The time in parentheses is attributed to a photoproduct (see text). The weighted deviations, expressed in $\sigma$ (expected deviations), the autocorrelation functions $A-C$, and the values for $\chi^{2}$ are also indicated. Excitation wavelength: $297 \mathrm{~nm}$. is shown in Fig. 4. The decays are made up of two exponentials, both with a short decay time $\tau_{2}$ of 12 ps and a longer time $\tau_{1}$ of $0.79 \mathrm{~ns}$. The third decay time of $14.3 \mathrm{~ns}$ appearing in the two decays is attributed to a photoproduct, as its contribution to the total fluorescence decay increases with the duration of the laser excitation (Section 3.5).

$$
\begin{aligned}
& i_{\mathrm{f}}(\mathrm{LE})=A_{11} \exp \left(-t / \tau_{1}\right)+A_{12} \exp \left(-t / \tau_{2}\right), \\
& i_{\mathrm{f}}(\mathrm{ICT})=A_{21} \exp \left(-t / \tau_{1}\right)+A_{22} \exp \left(-t / \tau_{2}\right), \\
& A=A_{12} / A_{11} .
\end{aligned}
$$

From the decay times $\tau_{2}$ and $\tau_{1}$ together with the amplitude ratio $A$ (Eqs. (3) and (5)) and the model compound lifetime $\tau_{0}$, the ICT rate constants $k_{a}$ and $k_{d}$ and the lifetime $\tau_{0}^{\prime}(\mathrm{ICT})$ can be determined [4,20] (see Table 3). The fluorescence lifetime of DMABN in $n$-hexane was taken for $\tau_{0}$, as dual emission is not observed with this system (Fig. 1). The radiative rate constants $k_{\mathrm{f}}(\mathrm{LE})$ and $k_{\mathrm{f}}^{\prime}(\mathrm{ICT})$ can be determined from the fluorescence quantum yields $\Phi(\mathrm{LE})$ and $\Phi^{\prime}$ (ICT) (see Tables 1 and 3).The observation that the amplitude ratio $A_{22} / A_{21}$ (Eq. (4)) is equal to -1.0 (see Fig. 4), shows that the ICT state of DIABN is not formed by direct excitation from the ground state, but originates exclusively from the primarily formed LE state $[4,5,20]$.

\subsection{1. $k_{a}, \tau_{0}^{\prime}(I C T)$ and $k_{\mathrm{ISC}}^{\prime}(I C T)$}

For the ICT reaction of DIABN in $n$-hexane at $-90^{\circ} \mathrm{C}$, a rate constant $k_{a}$ of $8 \times 10^{10} \mathrm{~s}^{-1}$ is obtained. The lifetime $\tau_{0}^{\prime}$ (ICT) equals $0.79 \mathrm{~ns}$. As there is no evidence for appreciable internal conversion from the ICT state (Section 3.7.), only fluorescence and ISC deactivate the ICT state and $1 / \tau_{0}^{\prime}(\mathrm{ICT})=$ $k_{\text {ISC }}^{\prime}(\mathrm{ICT})+k_{\mathrm{f}}^{\prime}(\mathrm{ICT})$. From the data in Table 3 , it is seen that $k_{\mathrm{f}}^{\prime}(\mathrm{ICT})$ can be neglected with respect to $k_{\text {ISC }}^{\prime}(\mathrm{ICT}): 1 / \tau_{0}^{\prime}(\mathrm{ICT})=k_{\text {ISC }}^{\prime}$ (ICT). This leads to $k_{\text {ISC }}^{\prime}\left(\right.$ ICT) values of 1.27 and $1.06 \times 10^{9} \mathrm{~s}^{-1}$ at -90 and $25^{\circ} \mathrm{C}$, respectively. Using these data, it follows from $\Phi_{\text {ISC }}^{\prime}(\mathrm{ICT})=k_{\mathrm{ISC}}^{\prime}(\mathrm{ICT}) \cdot \tau_{0}^{\prime}(\mathrm{ICT})$ that the triplet yield from the ICT state $\Phi_{\text {ISC }}^{\prime}$ (ICT) amounts to 0.995 at $-90^{\circ} \mathrm{C}$ and 0.992 at $25^{\circ} \mathrm{C}$ (see Table 1). These 
Table 3

Fluorescence decay times $\tau_{2}$ and $\tau_{1}$ (Eqs. (3) and (4)) and $\tau_{0}$, amplitude ratio $A$ (Eq. (5)), rate constants of the forward $\left(k_{a}\right)$ and backward $\left(k_{d}\right)$ ICT reactions, ICT fluorescence lifetime $\tau_{0}^{\prime}(\mathrm{ICT})$, the LE and ICT radiative rate constants $k_{\mathrm{f}}(\mathrm{LE})$ and $k_{\mathrm{f}}^{\prime}(\mathrm{ICT})$ and the rate constant $k_{\text {ISC }}^{\prime}$ (ICT) of the intersystem crossing (ISC) from the ICT state

\begin{tabular}{|c|c|c|c|c|c|c|c|c|c|c|c|}
\hline $\begin{array}{l}T \\
\left({ }^{\circ} \mathrm{C}\right)\end{array}$ & $\begin{array}{l}\tau_{2} \\
\text { (ns) }\end{array}$ & $\begin{array}{l}\tau_{1} \\
\text { (ns) }\end{array}$ & $A$ & $\begin{array}{l}\tau_{0} \\
\text { (ns) }\end{array}$ & $\begin{array}{l}k_{a} \\
\left(10^{11} \mathrm{~s}^{-1}\right)\end{array}$ & $\begin{array}{l}k_{d} \\
\left(10^{8} \mathrm{~s}^{-1}\right)\end{array}$ & $\begin{array}{l}\tau_{0}^{\prime}(\mathrm{ICT}) \\
(\mathrm{ns})\end{array}$ & $\begin{array}{l}k_{\mathrm{f}}(\mathrm{LE}) \\
\left(10^{7} \mathrm{~s}^{-1}\right)\end{array}$ & $\begin{array}{l}k_{\mathrm{f}}^{\prime}(\mathrm{ICT}) \\
\left(10^{6} \mathrm{~s}^{-1}\right)\end{array}$ & $k_{\mathrm{f}}^{\prime}(\mathrm{ICT}) k_{\mathrm{f}}(\mathrm{LE})$ & $\begin{array}{l}k_{\text {ISC }}^{\prime}(\text { ICT }) \\
\left(10^{9} \mathrm{~s}^{-1}\right)\end{array}$ \\
\hline 25.5 & 0.003 & 0.94 & $>430$ & $3.42^{\mathrm{a}}$ & $3.4^{\mathrm{b}}$ & $<8$ & 0.94 & $6^{\mathrm{c}}$ & $9^{d}$ & $0.17^{\mathrm{e}}$ & $1.0^{\mathrm{f}}$ \\
\hline-90.3 & 0.012 & 0.79 & $>210$ & $4.10^{\mathrm{a}}$ & 0.8 & $<4$ & 0.79 & $4^{c}$ & $6^{\mathrm{d}}$ & $0.15^{\mathrm{e}}$ & $1.3^{\mathrm{g}}$ \\
\hline
\end{tabular}

${ }^{a}$ Fluorescence decay time $\tau_{0}$ of DMABN in $n$-hexane.

${ }^{b}$ From data in Fig. 5 (see Fig. 4)

${ }^{\mathrm{c}}$ From $\Phi(\mathrm{LE})$ (see Table 1 and the expression $k_{f}=\Phi(\mathrm{LE})\left(1 / \tau_{0}+1 / \tau_{0}^{\prime} \cdot k_{a} /\left(k_{d}+1 / \tau_{0}^{\prime}\right)\right)$ (see text).

${ }^{\mathrm{d}}$ From $\Phi^{\prime}(\mathrm{ICT})$ (see Table 1) and the expression $k_{f}^{\prime}=\Phi^{\prime}(\mathrm{ICT})\left(1 / \tau_{0}^{\prime}+1 / \tau_{0} \cdot\left(k_{d}+1 / \tau_{0}^{\prime}\right) / k_{a}\right)$ (see text)

${ }^{\mathrm{e}}$ From the data for $\Phi^{\prime}(\mathrm{ICT}) / \Phi(\mathrm{LE})$ in Table 1 and the expression (Ref. [4]) $\Phi^{\prime}(\mathrm{ICT}) / \Phi(\mathrm{LE})=k_{\mathrm{f}}^{\prime}(\mathrm{ICT}) / k_{\mathrm{f}}(\mathrm{LE}) \cdot k_{a} /\left(k_{d}+1 / \tau_{0}^{\prime}(\mathrm{ICT})\right)$

${ }^{\mathrm{f}}$ From $k_{\mathrm{ISC}}^{\prime}=\Phi^{\prime}$ (ISC) $/ \tau_{0}^{\prime}(\mathrm{ICT})$ (see Table 1$)$.

${ }^{\mathrm{g}}$ From $k_{\mathrm{ISC}}^{\prime}(\mathrm{ICT})=1 / \tau_{0}^{\prime}(\mathrm{ICT})-k_{\mathrm{f}}^{\prime}(\mathrm{ICT})$, under the assumption that internal conversion can be neglected (see data in this table and text (Section 3.7). 
results show that ISC is the predominant deactivation pathway of the ICT state.

\subsection{2. $\mathbf{A}$ and $k_{d}$}

The amplitude ratio $A=A_{12} / A_{11}$ (Eq. (5)) has at $-90^{\circ} \mathrm{C}$ a value of 210 (Table 3 ), which is a lower limit due to the presence of photoproducts (Section 3.5). As $A$ is approximately equal to $k_{a} / k_{d}$ under the present conditions $[4,20]$, this means that the rate constant of the forward ICT reaction $k_{a}$ is at least 210 times larger than the thermal back reaction $k_{d}$, i.e., $k_{d}$ is smaller than $4 \times 10^{8} \mathrm{~s}^{-1}$. It should be noted in this connection, that the LE fluorescence quantum yield $\Phi_{\mathrm{LE}}$ of DIABN in $n$-hexane at $-90^{\circ} \mathrm{C}$ is very small: $6 \times 10^{-4}$ (Table 1 ). As a consequence, minor amounts of photoproducts or other impurities (Section 3.5) with fluorescence decay times in the nanosecond time range $[4,18,20]$ will lead to a decrease of the amplitude ratio $A$. The value obtained here for $k_{d}$ from $A$ and $\tau_{2}$ (Table 3) therefore is an upper limit. It cannot be excluded that $k_{d}$ for DIABN in $n$-hexane at $-90^{\circ} \mathrm{C}$ is in fact equal to zero.

\subsection{Fluorescence decays as a function of tempera- ture: DIABN in n-hexane}

The fluorescence decay of DIABN in $n$-hexane was measured as a function of temperature. Identical results were obtained at the two excitation wavelengths 297 and $276 \mathrm{~nm}$. The short decay time $\tau_{2}$ decreases with increasing temperature, from $12 \mathrm{ps}$ at $-90^{\circ} \mathrm{C}$ (Fig. 4) to 3 ps at $25^{\circ} \mathrm{C}$ (see Fig. 5). As $\tau_{2}$ is practically equal to the reciprocal of the ICT rate constant $k_{a}$ under the prevailing experimental conditions $\left(\tau_{2}<<\tau_{1}[4,20]\right)$, the activation energy $E_{a}$ can be obtained from an Arrhenius plot of $\tau_{2}$. From the line fitting the data points in Fig. 5, an energy $E_{a}$ of $6 \mathrm{~kJ} \mathrm{~mol}^{-1}$ and a pre-exponential factor $k_{a}^{o}$ of $3.5 \times 10^{12} \mathrm{~s}^{-1}$ result (Table 2), in agreement with the approximate value of $4 \pm 1 \mathrm{~kJ} \mathrm{~mol}^{-1}$ determined from a Stevens-Ban plot (Section 3.6). The activation energy $E_{d}$ of the ICT $\rightarrow$ LE rate constant $k_{d}$ and hence the ICT stabilisation enthalpy $\Delta H$ cannot be determined with sufficient accuracy, because of the uncertainty in the amplitude ratio $A$ (Section 3.8).

With DMABN in toluene, an activation energy $E_{a}$ of $8 \mathrm{~kJ} \mathrm{~mol}^{-1}$ has been determined [4] and $E_{a}$

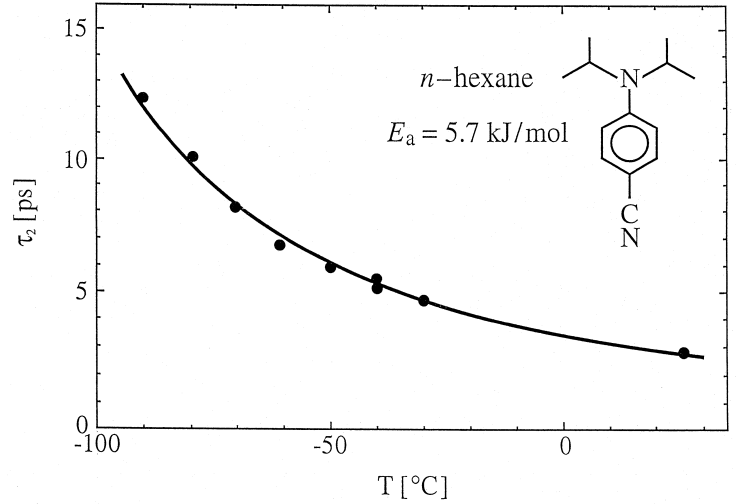

Fig. 5. Plot of the short fluorescence decay time $\tau_{2}$ of DIABN in $n$-hexane as a function of temperature. The line through the data points represents a least-squares fit, resulting in an ICT activation energy $E_{a}$ of $5.7 \mathrm{~kJ} \mathrm{~mol}^{-1}$ and a pre-exponential factor $k_{a}^{0}$ of $3.5 \times 10^{12} \mathrm{~s}^{-1}$ (see text). Excitation wavelengths: 276 and 297 $\mathrm{nm}$.

becomes larger when the solvent polarity decreases [34], from $5 \mathrm{~kJ} \mathrm{~mol}^{-1}$ in diethyl ether up to $20 \mathrm{~kJ}$ $\mathrm{mol}^{-1}$ in di( $n$-pentyl) ether [35]. For the nonpolar solvent $n$-hexane a still higher barrier is expected. It is therefore concluded that the absence of dual fluorescence with DMABN in $n$-hexane is, apart from an unfavourable (probably positive) $\Delta H$ [19,31,35], caused by the fact that its ICT activation energy is considerably larger than that of DIABN.

\section{Conclusions}

With DIABN, efficient ICT and dual fluorescence is observed in nonpolar alkane solvents such as $n$-hexane and isopentane, from room temperature down to -90 or $-130^{\circ} \mathrm{C}$, respectively, in clear contrast to what is found with DMABN. The fluorescence spectrum of DIABN in these alkanes predominantly consists of an emission from the ICT state, with a $\Phi^{\prime}(\mathrm{ICT}) / \Phi(\mathrm{LE})$ ratio of around 27 in $n$ hexane at $25^{\circ} \mathrm{C}$. An ICT dipole moment $\mu_{\mathrm{e}}$ (ICT) of $18 \mathrm{D}$ is obtained for DIABN from solvatochromic measurements, similar to that of DMABN.

From an analysis of LE and ICT fluorescence decays it is found that with DIABN a fast ICT reaction occurs, with a rate constant $k_{a}$ of $3.4 \times 10^{11}$ $\mathrm{s}^{-1}$ at $25^{\circ} \mathrm{C}$ in $n$-hexane, slowing down somewhat to 
$8 \times 10^{10} \mathrm{~s}^{-1}$ at $-90^{\circ} \mathrm{C}$. This reaction has an activation energy $E_{a}$ of $6 \mathrm{~kJ} \mathrm{~mol}^{-1}$. Efficient ISC, with a yield $\Phi_{\text {ISC }}$ of 0.94 at $25^{\circ} \mathrm{C}$, takes place from the ICT state.

The occurrence of fast ICT with DIABN in alkane solvents such as $n$-hexane and isopentane mainly results from the considerably smaller energy gap $\Delta E\left(S_{1}, S_{2}\right)$ of DIABN as compared with DMABN, which leads to a decrease in the activation energy $E_{a}$ of the ICT reaction, in support of the PICT model $[2,4,9,10]$. With DIABN and DMABN the ICT activation energy $E_{a}$ is not predominantly determined by the change in pyramidality of the amino nitrogen $\mathrm{N}(1)$, in contrast to what has been observed $[9,10,13]$ with 4-(azetidinyl)benzonitrile (P4C).

\section{Acknowledgements}

The generous support of the Volkswagen Foundation (Project Intra- and Intermolecular Electron Transfer) is gratefully acknowledged. We are thankful to the German Research Council (DFG) for a postdoctoral fellowship awarded to M.G. E.H. and J.-L. R. thank the Swiss National Science Foundation for support (Project Nr. 20-53568.98).

\section{References}

[1] W. Rettig, B. Bliss, K. Dirnberger, Chem. Phys. Lett. 305 (1999) 8.

[2] K.A. Zachariasse, Chem. Phys. Lett. 320 (2000) 8.

[3] C. Chudoba, A. Kummrow, J. Dreyer, J. Stenger, E.T.J. Nibbering, T. Elsaesser, K.A. Zachariasse, Chem. Phys. Lett. 309 (1999) 357.

[4] Yu.V. Il'ichev, W. Kühnle, K.A. Zachariasse, J. Phys. Chem. 102 (1998) 5670.

[5] K.A. Zachariasse, M. Grobys, E. Tauer, Chem. Phys. Lett. 274 (1997) 372.

[6] W. Rettig, in: J. Mattay (Ed.), Topics in Current Chemistry, Electron Transfer I, vol. 169, Springer, Berlin, 1994, p. 253.

[7] Z.R. Grabowski, K. Rotkiewicz, A. Siemiarczuk, D.J. Cowley, W. Baumann, Nouv. J. Chim. 3 (1979) 443.

[8] W. Rettig, Angew. Chem. Int. Ed. Engl. 25 (1986) 971.

[9] K.A. Zachariasse, M. Grobys, Th. von der Haar, A. Hebecker, Yu.V. Il'ichev, Y.-B. Jiang, O. Morawski, W. Kühnle, J. Photochem. Photobiol. A: Chem. 102 (1996) 59.
[10] K.A. Zachariasse, M. Grobys, Th. von der Haar, A. Hebecker, Yu.V. Il'ichev, O. Morawski, I. Rückert, W. Kühnle, J. Photochem. Photobiol. A: Chem. 105 (1997) 373.

[11] A. Heine, R. Herbst-Irmer, D. Stalke, W. Kühnle, K.A. Zachariasse, Acta Cryst. B 50 (1994) 363.

[12] G. Berden, J. van Rooy, W.L. Meerts, K.A. Zachariasse, Chem. Phys. Lett. 278 (1997) 373.

[13] Th. von der Haar, A. Hebecker, Yu.V. Il'ichev, Y.-B. Jiang, W. Kühnle, K.A. Zachariasse, Recl. Trav. Chim. Pays-Bas 114 (1995) 430.

[14] M. Oki, Applications of Dynamic NMR Spectroscopy to Organic Chemistry, VCH, Weinheim, 1985.

[15] R. Boese, D. Bläser, M.Y. Antipin, V. Chaplinski, A. de Meijere, J. Chem. Soc., Chem. Commun., 1998, p. 781.

[16] H. Bock, I. Göbel, Z. Havlas, S. Liedle, H. Oberhammer, Angew. Chem. Int. Ed. Engl. 30 (1991) 187.

[17] A.J. Blake, E.A.V. Ebsworth, A.J. Welch, Acta Cryst. C 40 (1984) 413.

[18] E. Lippert, W. Lüder, F. Moll, W. Nägele, H. Boos, H. Prigge, I. Seibold-Blankenstein, Angew. Chem. 73 (1961) 695.

[19] K.A. Zachariasse, Th. von der Haar, A. Hebecker, U. Leinhos, W. Kühnle, Pure Appl. Chem. 65 (1993) 1745.

[20] U. Leinhos, W. Kühnle, K.A. Zachariasse, J. Phys. Chem. 95 (1991) 2013.

[21] R. Reynaud, Bull. Soc. Chim. Fr., 1967, p. 2686.

[22] S.-D. Yoh, Y. Tsuno, M. Fujio, M. Sawada, Y. Yukawa, J. Chem. Soc. Perkin Trans. 2 (1989) 7.

[23] J.N. Demas, G.A. Crosby, J. Phys. Chem. 75 (1971) 991.

[24] I. Carmichael, W.P. Helman, G.L. Hug, J. Phys. Chem. Ref. Data 16 (1987) 239.

[25] L. Biczok, T. Berces, H. Inoue, J. Phys. Chem. A 103 (1999) 3837.

[26] A. Demeter, S. Braslavski, unpublished results.

[27] M. Noltemeyer, K.A. Zachariasse, in preparation.

[28] T. Thormann, P.W. Thulstrup, K.A. Zachariasse, unpublished results.

[29] W. Liptay, in: E.C. Lim (Ed.), Excited states, vol. 1, Academic Press, New York, 1974, p. 129.

[30] W. Baumann, H. Bischof, J.-C. Brittinger, W. Rettig, K Rotkiewicz, J. Photochem. Photobiol. A: Chem. 64 (1992) 49.

[31] Yu.V. Il'ichev, W. Kühnle, K.A. Zachariasse, Chem. Phys. 211 (1996) 441.

[32] J.J. Gajewski, K.E. Gilbert, L. McKelvey, in: D. Liotta (Ed.), Advances in Molecular Modelling, vol. II, JAI Press, Greenwich, CN, 1990, p. 65.

[33] W. Schuddeboom, S.A. Jonker, J.M. Warman, U. Leinhos, W. Kühnle, K.A. Zachariasse, J. Phys. Chem. 96 (1992) 10809.

[34] J.M. Hicks, M.T. Vandersall, E.V. Sitzmann, K.B. Eisenthal, Chem. Phys. Lett. 135 (1987) 413.

[35] U. Leinhos, Ph.D. Thesis, University Göttingen 1991. 